\title{
Development of Life Support System Technologies for Human Lunar Missions
}

\author{
Daniel J. Barta and Michael K. Ewert \\ NASA Johnson Space Center, Houston, Texas, USA
}

\begin{abstract}
With the Preliminary Design Review (PDR) for the Orion Crew Exploration Vehicle planned to be completed in 2009, Exploration Life Support (ELS), a technology development project under the National Aeronautics and Space Administration's (NASA) Exploration Technology Development Program, is focusing its efforts on needs for human lunar missions. The ELS Project's goal is to develop and mature a suite of Environmental Control and Life Support System (ECLSS) technologies for potential use on human spacecraft under development in support of U.S. Space Exploration Policy. ELS technology development is directed at three major vehicle projects within NASA's Constellation Program (CXP): the Orion Crew Exploration Vehicle (CEV), the Altair Lunar Lander and Lunar Surface Systems, including habitats and pressurized rovers. The ELS Project includes four technical elements: Atmosphere Revitalization Systems, Water Recovery Systems, Waste Management Systems and Habitation Engineering, and two cross cutting elements, Systems Integration, Modeling and Analysis, and Validation and Testing. This paper will provide an overview of the ELS Project, connectivity with its customers and an update to content within its technology development portfolio with focus on human lunar missions.
\end{abstract}

\section{INTRODUCTION}

The Exploration Life Support (ELS) Project is one of over twenty technology development projects managed by NASA's Exploration Technology Development Program (ETDP), under the guidance of the Advanced Capabilities Division of the NASA's Exploration Systems Mission Directorate (ESMD). ELS was originally chartered to perform research and technology development (R\&TD) toward meeting specific critical architectural functional needs identified by the Exploration Systems Architecture Study (ESAS) in the categories Environmental Control and Life Support (ECLS) and Crew Support and Accommodations, with specific focus on atmospheric management $\mathrm{CO}_{2} /$ contaminants and moisture removal systems, advanced air and water recovery systems, and habitability systems including waste management and hygiene $[1,2]$. Other technical areas often associated with ECLS, including thermal control, environmental monitoring, and fire protection, were chartered as separate technology development projects.

The ELS Project's chief objective is to develop and mature relevant technologies that meet mission requirements and fill capability gaps or significantly improve the efficiency, safety, and reliability over the state of the art, providing risk reduction and developmental economy to flight projects [3]. CxP's policy is to ensure that technologies needed for Constellation projects are matured to technology readiness level (TRL) 6 in time to support system-level (Level III) PDRs [4]. With the PDR for the Orion Crew Exploration Vehicle planned to be completed in 2009 and the ELS Project's technology development tasks for CEV largely completed, the focus of the ELS Project's portfolio has shifted to emphasize technology needs for human lunar missions.

\section{TECHNOLOGY NEEDS FOR HUMAN LUNAR MISSIONS}

Each technology project manager is directed by ETDP to participate with technology development customers to 
understand infusion opportunities, to establish customer advocacy, and to drive the technology development towards meeting customer capability needs [5]. CXP is operating primarily under a "technology pull" strategy, which is outlined in the Constellation Program Technology Insertion Strategy Document [4]. A requirements-driven approach is used to determine CxP technology needs. This strategy was put in place to ensure that ESMD's technology investments are traceable to baseline requirements, validate the mapping of technology investments to mission needs and reduce technical and programmatic risks.

Technology needs are reviewed and prioritized by CxP's Technology Prioritization Panel (TPP) on a yearly basis. The third TPP was conducted in fiscal year (FY) 2009. The TPP has membership that includes representatives from various requirement owner organizations, including System Integration Groups, Constellation Project Offices, and Architecture Teams [6]. Needs are categorized as based on criticality or priority and are associated with a specific mission, including Initial Operational Capability (CEV to the International Space

Table 1. Lunar Transport and Lunar Surface technology needs applicable to ECLSS, ordered by mission, category, then ID.

\begin{tabular}{|c|c|c|c|}
\hline ID & Title & Category* & Mission \\
\hline 105 & Lunar Dust Filtration & Critical & Lunar Transport \\
\hline 594 & Advanced Airlock/Suitlock with Dust Filtration & Critical & Lunar Transport \\
\hline 607 & CO2 \& Moisture Removal System & Critical & Lunar Transport \\
\hline 610 & High Pressure Oxygen & Critical & Lunar Transport \\
\hline 103 & Targeted Trace Contaminant Control & Highly Desirable & Lunar Transport \\
\hline 107 & Deployable Post-Fire Cleanup Device & Highly Desirable & Lunar Transport \\
\hline 475 & Biocide Development & Highly Desirable & Lunar Transport \\
\hline 476 & Urine Pretreatment & Highly Desirable & Lunar Transport \\
\hline 477 & Urine Receptacle Assembly & Highly Desirable & Lunar Transport \\
\hline 501 & High Pressure Oxygen for Lander & Highly Desirable & Lunar Transport \\
\hline 627 & Lander Dust Mitigation & Highly Desirable & Lunar Transport \\
\hline 678 & Improved Trace Contaminant Control Catalysts and Sorbents & Highly Desirable & Lunar Transport \\
\hline 408 & Quiet Fans & Desirable & Lunar Transport \\
\hline 617 & Quiet Fans/Compressors and Small Mufflers & Desirable & Lunar Transport \\
\hline 618 & Tox/Dust/Emergency Breathing Mask & Desirable & Lunar Transport \\
\hline 112 & Improved $\mathrm{CO}_{2}$ Removal for Loop Closure & Critical & Lunar Surface \\
\hline 113 & Carbon Dioxide Reduction & Critical & Lunar Surface \\
\hline 119 & Water Recovery from Brine & Critical & Lunar Surface \\
\hline 469 & Lunar Dust Filtration & Critical & Lunar Surface \\
\hline 517 & Life Support Water Recovery & 1 & Lunar Surface \\
\hline 522 & Life Support Air Revitalization & 1 & Lunar Surface \\
\hline 623 & Dust/Regolith Mitigation Techniques within Habitable Cabin & Critical & Lunar Surface \\
\hline 625 & Dust Control/Removal Airborne Dust & Critical & Lunar Surface \\
\hline 634 & Brine Water Recovery & Critical & Lunar Surface \\
\hline 638 & Carbon Dioxide Reduction & Critical & Lunar Surface \\
\hline 639 & Water Recovery with Limited Resupply & Critical & Lunar Surface \\
\hline 644 & Carbon Dioxide Reduction & Critical & Lunar Surface \\
\hline 645 & High Pressure Oxygen Supply & Critical & Lunar Surface \\
\hline 115 & Improved/Targeted Trace Contaminant Control & Highly Desirable & Lunar Surface \\
\hline 480 & Urine Pretreatment & Highly Desirable & Lunar Surface \\
\hline 649 & Simplified Robust Partial-Gravity Water Processing \& Phase Separation & Highly Desirable & Lunar Surface \\
\hline 667 & Waste Stabilization and Dewatering & Highly Desirable & Lunar Surface \\
\hline 675 & Improved Urine Pretreatment Methods & Highly Desirable & Lunar Surface \\
\hline 681 & Sustainable Food Production, Processing and Preparation & Highly Desirable & Lunar Surface \\
\hline 685 & Deployable Post-Fire Cleanup & Highly Desirable & Lunar Surface \\
\hline 687 & Advanced Clothing/Fabric Cleaning Systems & Highly Desirable & Lunar Surface \\
\hline 699 & In-situ methane production & Highly Desirable & Lunar Surface \\
\hline 985 & Waste Stabilization and Volume Reduction & 2 & Lunar Surface \\
\hline 712 & Quiet Fans and Ventilation Acoustic Emission Attenuation Techniques & Desirable & Lunar Surface \\
\hline 715 & LED Lighting & Desirable & Lunar Surface \\
\hline
\end{tabular}

*Category designations are as follows: $\mathrm{C}=$ "Critical", $\mathrm{HD}=$ "Highly Desirable", $\mathrm{D}=$ "Desirable". Data from references

6 \& 7. Three new needs identified during the third annual TPP in FY09 have been added and carry the following category designations: 1="Must Fund For FY11", 2="Need to Fund As Funding Becomes Available". 
Station), Lunar Transit (CEV to lunar orbit and Lunar Lander) and Lunar Surface (including lunar habitats and pressurized rovers). Technology needs applicable to ELS for lunar missions are listed in Table 1. In some cases multiple needs address the same technical area. This may be due to similar submissions from different CxP customers or to reflect unique needs for specific vehicles or applications. More specific information on needs, requirements, architectures, design baselines and operational scenarios applicable to ECLSS is available $[7,8,9,10]$.

\section{EXPLORATION LIFE SUPPORT (ELS) PROJECT ORGANIZATION}

The ELS Project is managed from Johnson Space Center and includes Marshall Spaceflight Center, Kennedy Space Center, Ames Research Center and Glenn Research Center as participating Centers [3]. The Project is organized into seven elements including a project management office. The project office is responsible for project implementation, following mandatory technology development project requirements [11] and is responsible to the sponsoring program, ETDP [5]. There are four technology development elements within ELS: Atmosphere Revitalization Systems (ARS); Water Recovery Systems (WRS); Waste Management Systems (WMS); and Habitation Engineering. Two elements are cross-cutting, providing support to the four technology elements: Systems Integration, Modeling, and Analysis (SIMA), and Validation and Testing (V\&T). The Work Breakdown Structure (WBS) for ELS is consistent with NPR 7120.8 and is tailored toward the unique needs for spacecraft ECLSS and habitation systems (Table 2).

SYSTEMS ANALYSIS - The ELS project uses systems analysis to guide investments in technology development and evolution of life support system architectures. The Systems Integration, Modeling and Analysis (SIMA) Element of ELS fulfills this responsibility and has developed various analytical tools and resources. SIMA helps determine the equivalent system mass (ESM) of competing technologies for Constellation missions as well as doing more detailed performance analysis. ESM is an analysis method developed by SIMA, which combines the launch mass of hardware and consumables with mass penalties for volume, power and crew time requirements into a single 'equivalent system mass [12].

Although lunar exploration missions are becoming better defined, many assumptions must still be made in order to carry out meaningful analyses. Therefore, SIMA has developed and maintains various products to document mission details, analysis methods and necessary assumptions. The primary documents are listed and briefly described in Table 3 . Within this framework, more meaningful engineering trade-off studies, architecture assessments and parametric analyses can be conducted. In 2008, the Exploration Life Support
Baseline Values and Assumptions Document, the Exploration Life Support Reference Missions Document and the Exploration Life Support Requirements Document were all updated to reflect the most recent information available from the Constellation program [13, $14,15]$.

Examples of recent ELS studies completed by SIMA include "Exploration Life Support R\&TD Metric of the Lunar Outpost" [16], "Bosch Carbon Dioxide Reduction System Model" [17], "Laundry Study for Constellation" [18] and "SPR ECLSS Sizing Analysis: Carbon Dioxide and Humidity Control" [19].

Systems analyses such as these lead to findings concerning optimization of life support systems for exploration missions. For example:

- Atmosphere, water and food systems understandably require significant launch mass from Earth to support humans at a lunar outpost, but this amount can be cut in half by using advanced technologies under development by ELS compared to state-of-the-art [16].

- Water based laundry systems trade well for a lunar outpost when a brine processor is used [18].

- The use of 2 spacesuit-sized $\mathrm{CO}_{2}$ removal units in the lunar rover will meet requirements for nonexercise nominal and contingency cases, but may not meet requirements for exercise cases [19].

In addition to creating original models and studies, SIMA analyzes test data produced by other elements of ELS, such as "Post-test Modeling and Analysis of Phase I CAMRAS/Constellation Suit Integrated Test" [20]. SIMA has been heavily involved with subsequent tests of the CAMRAS technology as well as water distillation technology testing [21].

VALIDATION AND TESTING - Through the process of technology development and maturation, component or breadboard validation is performed in laboratory environments and then moves to testing in relevant environments. This second cross cutting element (supports all other ELS technical elements) provides this later function and is composed of two sub-elements, Flight Experiments and Integrated Testing.

Flight Experiments - The Flight Experiments technical element manages testing of technologies under hypogravity and microgravity conditions in order to complement the activities conducted in ground laboratories and ground test bed facilities. Process technologies under development by ELS for lunar missions will be assessed for gravity sensitivity and tested in the appropriate relevant environment to assure that the hardware performs as designed.

The Flight Experiment element technical approach is to schedule up to two flight campaigns for each fiscal year using commercial or government-owned reduced gravity 
Table 2. ELS Project work breakdown structure with relevant lunar mission needs and technology development tasks.

\begin{tabular}{|c|c|c|}
\hline WBS Title & $\begin{array}{l}\text { Specific Needs } \\
\text { Addressed* }\end{array}$ & Technologies** \\
\hline \multicolumn{3}{|l|}{01 Project Management } \\
\hline \multicolumn{3}{|l|}{$\begin{array}{l}.02 \text { Systems Integration, Modeling, and } \\
\text { Analysis }\end{array}$} \\
\hline $\begin{array}{c}\text {-01 Management and Systems } \\
\text { Engineering Support }\end{array}$ & $\dagger$ & \\
\hline -02 Systems Analysis \& Simulations & $t$ & \\
\hline -03 Technology Analysis and Simulations & + & \\
\hline -04 Reference Documents & + & \\
\hline -05 Test Analysis and Support & + & \\
\hline -06 Online Project Information System & + & \\
\hline \multicolumn{3}{|l|}{.04 Technology Development } \\
\hline \multicolumn{3}{|l|}{.04.01 Air Revitalization Systems (ARS) } \\
\hline $\begin{array}{l}\text {-01 Carbon Dioxide Partial Pressure } \\
\text { Control }\end{array}$ & $112,522,607$ & CAMRAS, SBAR, LPCOR, NGARS, ESS \\
\hline -02 Control Trace VOC Concentrations & $\begin{array}{l}103,107,115,522 \\
618,678,685\end{array}$ & $\begin{array}{l}\text { VOC Sorbents and catalysts, ESS, ATCC, } \\
\text { Toxic Atmosphere Recovery }\end{array}$ \\
\hline -03 Particulate Matter Removal & $\begin{array}{c}105,469,522,594 \\
623,625,627\end{array}$ & Atmospheric dust removal, vacuum cleaner \\
\hline -04 Resource Recovery and Recycling & $113,522,638,644$ & $\begin{array}{l}\text { Sabatier, Bosch, methane pyrolysis, SOE, } \\
\text { TSAC }\end{array}$ \\
\hline -05 Atmospheric Gas Storage and Supply & $501,610,645$ & $\begin{array}{l}\text { High pressure oxygen (swing bed \& } \\
\text { mechanical compression, electrolysis), } \\
\text { Subcritical LOX Storage, ISRU integration }\end{array}$ \\
\hline-06 Supporting Infrastructure & $408,522,617,712$ & Quiet fan development \\
\hline \multicolumn{3}{|l|}{.04 .02 Water Recovery Systems (WRS) } \\
\hline $\begin{array}{l}-01 \text { Wastewater Pretreatment and } \\
\text { Storage Systems }\end{array}$ & $119,517,634$ & $\begin{array}{l}\text { Alternative urine pretreatment, cleansers, } \\
\text { detergents and personal care products }\end{array}$ \\
\hline $\begin{array}{l}\text {-02 Potable Water Disinfection and } \\
\text { Storage Systems }\end{array}$ & 475,517 & Alternative biocides, point of use filtration, \\
\hline $\begin{array}{l}-03 \text { Primary and Secondary Water } \\
\text { Processing Systems }\end{array}$ & $517,639,649$ & $\begin{array}{l}\text { CDS, DOC, OD, EWRS, VPCAR, } L W C W T \text {, } \\
\text { gravity dependent water processor, bioreactors }\end{array}$ \\
\hline -04 Improved Post-processing Systems & $517,639,649$ & Thermal, vapor phase and photo- catalysis \\
\hline -05 Water Recovery from Brine Systems & $119,517,634$ & $\begin{array}{l}\text { Several candidate technologies are under } \\
\text { evaluation }\end{array}$ \\
\hline \multicolumn{3}{|l|}{.04.03 Waste Management Systems (WMS) } \\
\hline $\begin{array}{l}-01 \text { Human Metabolic Waste } \\
\text { Management }\end{array}$ & 667 & Flexible Membrane Commode \\
\hline -02 Volume Reduction of Waste & 985 & Compaction, Heat Melt Compactor \\
\hline -03 Resource Recovery and Drying & $667,699,985$ & Waste drying, Heat Melt Compactor \\
\hline -04 Waste Mineralization & 699,985 & Pyrolysis, Incineration \\
\hline -05 Waste Stabilization and Storage & 667,985 & $\begin{array}{l}\text { Waste drying, Heat Melt Compactor, VOC } \\
\text { characterization }\end{array}$ \\
\hline \multicolumn{3}{|l|}{ 04.04 Habitation Engineering } \\
\hline $\begin{array}{l}\text {-01 Hygiene and Housekeeping } \\
\text { Technologies }\end{array}$ & $\begin{array}{l}477,105,469,522 \\
594,623,625,627\end{array}$ & Waste collection, vacuum cleaner \\
\hline-02 Interior Clothing Systems & 687 & Advanced clothing and laundry \\
\hline -03 Crew Accommodation Technologies & 681,715 & Cabin Solid State Lighting \\
\hline \multicolumn{3}{|l|}{05 Validation \& Testing } \\
\hline -01 Flight Experiments & 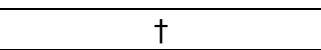 & \\
\hline -02 Integrated Testing & $\dagger$ & \\
\hline
\end{tabular}

* Need ID numbers shown. See Table 1 for titles of needs.

** See appendix for definitions of acronyms. Technologies in italics have historically had funding or may be subject to decision points.

${ }^{\dagger}$ SIMA and Validation \& Testing, by their cross-cutting nature, support all needs and technologies. 
aircraft. The flights provide the opportunity for experimenters to perform tests at various levels of gravity allowing for evaluations of hardware components early in the technology development sequence. Flight experiments on the ISS and other orbital or sub-orbital platforms may be considered if necessary for research or technology validation and if sufficient resources are available.

Integrated Testing - Integrated testing, in which candidate technologies are evaluated at subsystem or systems levels while interfacing with other life support hardware and challenged by real metabolic loads, is a necessary component of any technology development activity to advance a technology's maturity level. Integrated testing allows for demonstration of technology-to-technology interface compatibility and end-to-end functionality, including operability of life support hardware and software. Integrated testing is also useful in identifying weaknesses in technologies, allowing for more efficient focusing of future technology development resources. In some cases comparison tests are conducted to obtain data to assist in the down selection of competing technologies, such that the hardware with the best characteristics are chosen for further technology advancement.

Technologies are first evaluated in a laboratory setting using component or breadboard level hardware to demonstrate basic functionality and performance. Technology maturation is achieved as higher fidelity hardware is evaluated in relevant environments until ultimately a higher fidelity system/component, such as a brassboard or prototype, that adequately addresses scaling issues, is operated in a relevant environment to demonstrate operations under critical environmental conditions. For lunar missions, candidate technologies will require some level of evaluation under reduced atmospheric pressures, elevated oxygen levels and exposure to potential lunar dust particulates as may be present in a lunar lander and outpost.

Recently, integrated tests were conducted in support of validation of the $\mathrm{CO}_{2}$ and Moisture Removal Amine Swing-Bed (CAMRAS). The technology is under development for Orion and other future vehicles including Altair and pressurized rovers. Two integrated tests were completed in FY08 and FY09. The test series was titled the CAMRAS Constellation Suit Integrated Test (CCSIT). This three phase test program was developed for integrated testing of different hardware components (CAMRAS, prototype suit umbilicals, and pressure suits) alone or in configurations prototypic of the proposed ECLSS system for Orion. Phase I, completed June 1, 2008, involved human tests with CAMRAS in a cabin atmosphere revitalization configuration at ambient atmospheric pressure [20]. Phase 2, completed April 3, 2009, investigated CAMRAS performance in a suit-loop configuration, with enriched oxygen levels at suit pressure and at evacuated cabin conditions. Phase 3 , planned to be
Table 3. Exploration Life Support Reference Documents.

\begin{tabular}{|l|l|}
\hline Document Name & \multicolumn{1}{|c|}{ Description } \\
\hline $\begin{array}{l}\text { Exploration Life } \\
\text { Support Baseline } \\
\text { Values and } \\
\text { Assumptions } \\
\text { Document [13] }\end{array}$ & $\begin{array}{l}\text { Provides analysts, modelers, } \\
\text { and researchers a common } \\
\text { set of initial values and } \\
\text { assumptions as a baseline. } \\
\text { This baseline provides a } \\
\text { common point of origin from } \\
\text { which Systems Integration, } \\
\text { Modeling, and Analysis (SIMA) } \\
\text { Element studies can depart. }\end{array}$ \\
\hline $\begin{array}{l}\text { Exploration Life } \\
\text { Support Reference } \\
\text { Missions }\end{array}$ & $\begin{array}{l}\text { Provides the ELS Project with } \\
\text { several specific reference } \\
\text { missions that are likely } \\
\text { scenarios for human space } \\
\text { exploration, consistent with } \\
\text { Constellation plans as they } \\
\text { evolve. }\end{array}$ \\
\hline $\begin{array}{l}\text { Exploration Life } \\
\text { Support }\end{array}$ & $\begin{array}{l}\text { Outlines ELS Project } \\
\text { Requirements for ELS } \\
\text { Dechumements } \\
\text { technogies. Used as a tool } \\
\text { for Element Leads and } \\
\text { hardware developers. Based } \\
\text { on Constellation Program } \\
\text { requirements where available. }\end{array}$ \\
\hline
\end{tabular}

completed before the Orion CDR, will involve human subjects with and without pressure suits, at variable chamber pressures and oxygen concentrations. These tests have direct relevancy to Altair, as $\mathrm{CO}_{2}$ and moisture removal swing-bed technology is a strong candidate for use on a lunar lander.

\section{TECHNOLOGY PORTFOLIO}

The suite of specific technology development tasks within the ELS Project's portfolio is determined by CXP vehicle priorities, mission and technology trade studies, and available resources. The ELS portfolio is evaluated yearly and documented in the ELS Project Plan [3, 22]. The Work Breakdown Structure (WBS) for ELS is tailored toward the unique needs for spacecraft ECLSS and habitation systems. The WBS for ELS is given in Table 2, with corresponding needs and associated technology development tasks. A top level roadmap showing major technology tasks by year and mission is given in Figure 1. Key mission dates applicable to technology infusion are also shown. The figure illustrates that following the Orion PDR, emphasis will be on technology development supporting Altair and Lunar Surface Systems. Certain tasks, including waste management and trace gas contaminant control, were reduced in scope in FY09 due to conflicting priorities and 


\begin{tabular}{|l|l|l|l|l|l|}
\hline & 2007 & 2008 & 2009 & 2010 & 2011 \\
\hline Crew Exploration Vehicle (Orion)
\end{tabular}

Figure 1. Summary Roadmap for Exploration Life Support.

funding limitations, but the work is planned to be resumed in later years.

ATMOSPHERE REVITALIZATION SYSTEM (ARS) The Atmosphere Revitalization Systems (ARS) element objectives are to identify and to mature process technologies that directly address specific needs identified by CxP. Process technology maturation tasks are conducted for atmosphere revitalization functions that include $\mathrm{CO}_{2}$ partial pressure control; moisture removal; trace chemical contaminant control; particulate matter removal and disposal; atmospheric gas supply, storage, conditioning, and distribution; resource recovery, storage, conditioning, and recycling; and supporting infrastructure for the most promising process technologies. Emphasis for lunar lander includes carbon dioxide and moisture removal, cabin atmosphere particulate management directed at lunar dust, and high pressure oxygen systems in support of EVA recharge. These technologies also have applicability to Lunar Surface Systems, including pressurized habitats and rovers. The focus for LSS is closure of the ARS loop, including advanced carbon dioxide removal, carbon dioxide reduction, oxygen generation and trace contaminant control. Technologies and interfaces in support of EVA recharge, pressurized rovers and In Situ Resource Utilization (ISRU) will be investigated.

WATER RECOVERY SYSTEMS (WRS) - For lunar missions, the WRS element is primarily focused on development of closed-loop water recovery systems for Lunar Surface Systems, where recovery and production of potable water from wastewater with high levels of closure is necessary for mission success. Initial emphasis is on development and evaluation of physicochemical systems that can recover approximately $90 \%$ of wastewater to potable water quality. Technologies for further recovery of water from waste brines will be investigate to increase the level of closure. A set of competing technologies will be evaluated, with down selects/key decision points (KDP) to determine the systems for continued investment of technology funding.

WASTE MANAGEMENT SYSTEMS (WMS) - The WMS element is focused on the development of waste management technologies to recover resources, increase crew safety and performance, and protect planetary surfaces while decreasing mission cost. Technology gaps to be addressed for Lunar Surface Systems include water recovery from waste (supporting closure of the water loop), stabilization and odor control, waste/trash volume reduction, and disposal.

HABITATION ENGINEERING - Habitation Engineering is a distinct technology area directly applicable to human mission success. It provides crew interfaces to life support equipment and improves crew function, comfort, and quality of life to enhance crew productivity. Capabilities have historically been designed for Low Earth Orbit (LEO) missions with frequent resupply, and thus may not be sufficiently optimized for reliability, mass, volume, or autonomy which are critical design drivers for exploration missions. Development of 
systems for use in partial gravity, low atmospheric pressure and elevated oxygen concentrations will be a challenge. Habitation technologies focused at lunar missions include vehicle and habitat housekeeping/cleaning including dust mitigation, advanced clothing and laundry, and acoustic mitigation.

\section{CONCLUSION}

The Exploration Life Support technology development project is responsive to changes in architectures, requirements and organizational relationships as NASA's implementation of the U.S. Space Exploration Policy matures and as lunar architectures become more defined. With most tasks in support of the Orion Crew Exploration Vehicle nearing completion, the Exploration Life Support Project has shifted the emphasis of its research and technology development effort in support of critical needs for lunar transit and surface missions. Technology maturity dates of candidate technologies are aligned with key programmatic milestones for Altair and Lunar Surface Systems. The ELS project has a well established, active group of technologists throughout the agency dedicated to carrying out the U.S. Space Exploration Policy by reducing life support consumables and improving system performance and robustness.

\section{ACKNOWLEDGMENTS}

The authors wish to thank Chantel Whatley, Jeffrey McQuillan, the ELS Technical Element Leads, including Molly Anderson, James Broyan, John Fisher, Nancy Hall, Jay Perry, and Karen Pickering, and all participants within the ELS technology development community.

\section{REFERENCES}

1. National Aeronautics and Space Administration, "Exploration Systems Architecture Study", NASA, Washington, D.C., NASA-TM-2005-214062, 2006.

2. Chambliss, J., B. M. Lawson and D. J. Barta, "New Direction of NASA Exploration Life Support", SAE Paper 2006-01-2241, International Conference On Environmental Systems, July 17-20, 2006, Norfolk, Virginia, USA.

3. Barta, D.J., M.K. Ewert and J McQuillan. "Life Support System Technology Development Supporting Human Space Exploration", SAE Paper 2008-01-2185, International Conference On Environmental Systems, June 29-July 3, 2008, San Francisco, California, USA.

4. "Constellation Program Technology Insertion Strategy Document", (2007), NASA Document CxP 70079.

5. "Exploration Technology Development Program (ETDP) Research and Technology Program Plan", ETDP-0054, NASA Langley Research Center, Langley, VA, October 23, 2008.
6. Ham, L.J., "Constellation Program's Technology Development Needs", $3^{\text {rd }}$ Exploration Conference and Exhibit, Denver, CO, USA, February 26, 2008.

7. Carrasquillo, R.L., R.M. Bagdigian, M.S. Anderson and J.F. Lewis, "Life Support Requirements and Technology Challenges for NASA's Constellation Program", SAE Paper 2008-01-2018, International Conference On Environmental Systems, July 12July 16, 2009, Savannah, Georgia, USA.

8. Anderson, M.S., "Life Support Systems for Lunar Landers", SAE 2008-01-2172, 38th International Conference on Environmental Systems, June 29July 2, San Francisco, CA.

9. Bagdigian, R. M., "Considerations Regarding the Development of an Environmental Control and Life Support System for Lunar Surface Applications", SAE Paper 2008-01-2187, International Conference On Environmental Systems, June 29-July 3, 2008, San Francisco, California, USA.

10. Bagdigian, R. M., "Challenges with Deploying and Integrating Environmental Control and Life Support Functions in a Lunar Architecture with High Degrees of Mobility", SAE Paper 2009-01-2481, International Conference On Environmental Systems, July 12July 16, 2009, Savannah, Georgia, USA.

11. National Aeronautics and Space Administration, "NASA Research and Technology Program and Project Management Requirements", NPR 7120.8, Washington, D.C., 2008.

12. "Advanced Life Support Equivalent System Mass Guidelines Document," NASA TM-2003-212278, Levri, J.A., Drysdale, A. E., Ewert, M.K., Fisher, J.W., Hanford, A.J., Hogan, J. A., Jones, H.W., Joshi, J.A., and Vaccari, D.A., Authors, National Aeronautics and Space Administration, Ames Research Center, Moffett Field, CA.

13. Duffield, B.E., Editor, "Exploration Life Support Baseline Values and Assumptions Document," ESCG-4470-08-TEAN-DOC-0301, Engineering and Science Contract Group, Jacobs Sverdrup, Houston, Texas, USA, 2008.

14. Duffield, B.E., "Exploration Life Support Reference Missions Document," JSC 64109, NASA Johnson Space Center, Houston, Texas, USA, 2008.

15. Perka, A.T., Editor. "Exploration Life Support Requirements Document," JSC-65527A (CTSDADV-631, rev. A), NASA Johnson Space Center, Houston, Texas, 2008.

16. Yeh, H.Y., "Exploration Life Support R\&TD Metric of the Lunar Outpost - Fiscal Year 2008 (Revision A)", ESCG-4470-08-TEAN-DOC-0411, Engineering and Science Contract Group, Jacobs Sverdrup, Houston, TX, USA, February 17, 2009.

17. Fritts, S.D., "Bosch Carbon Dioxide Reduction System Model", ESCG-4470-08-TEAN-DOC-0282, Engineering and Science Contract Group, Jacobs Sverdrup, Houston, TX, USA, June 11, 2008.

18. Jeng, F., "Laundry Study for Constellation", ESCG4470-08-TEAN-DOC-0281, Engineering and 
Science Contract Group, Jacobs Sverdrup, Houston, TX, USA, August 18, 2008.

19. Lange, K.E., "SPR ECLSS Sizing Analysis: Carbon Dioxide and Humidity Control" presentation, Engineering and Science Contract Group, January 14, 2009.

20. Allada, R., "Post-test Modeling and Analysis of Phase I CAMRAS/Constellation Suit Integrated Test", $\quad$ ESCG-4470-08-TEAN-DOC-0310, Engineering and Science Contract Group, Jacobs Sverdrup, Houston, TX, USA, July 31, 2008.

21. Allada, R., L. A. Crenwelge, "Water Recovery Technology Development", ESCG-4470-08-TEANDOC-0383

22. "Technology Development Plan, Exploration Life Support (ELS)", Document Number JSC-65690A, NASA Johnson Space Center, Houston, TX, USA, October 21, 2008.

\section{CONTACT}

Daniel J. Barta

NASA Johnson Space Center

Mail Code EC1, Houston, TX, 77058

daniel.j.barta@nasa.gov

http://els.jsc.nasa.gov

\section{ACRONYMS}

ARC: Ames Research Center

ARS: Atmosphere Revitalization Systems

ATTCS: Advanced Trace Contaminant Control System BVAD: Baseline Values and Assumptions Document $\mathrm{CO}_{2}$ : Carbon Dioxide

CAMRAS: Carbon-Dioxide and Moisture Removal Amine Swing-Bed

CCSIT: Carbon Dioxide and Moisture Removal Amine Swing bed (CAMRAS) / Constellation Suit Integrated Test

CDR: Critical Design Review

CDS: Cascade Distillation System

CEV: Crew Exploration Vehicle

CFR: Carbon Formation Reactor

COTS: Commercial Off The Shelf

CR: Contractor Report

CTSD: Crew and Thermal Systems Division

CxP: Constellation Program

DOC: Direct Osmotic Concentration

ECLS: Environmental Control and Life Support

ECLSS: Environmental Control and Life Support

System

ELS: Exploration Life Support
ESAS: Exploration Systems Architecture Study

ESM: Equivalent System Mass

ESMD: Exploration Systems Mission Directorate

ESS: Engineered Structured Sorbents

ETDP: Exploration Technology Development Program

EVA: Extra-Vehicular Activity

EWRS: Exploration Water Recovery System

FY: Fiscal Year

GRC: Glenn Research Center

$\mathbf{H}_{2}$ : Hydrogen

HE: Habitation Engineering

HQ: Headquarters

IC: Initial Capability

ISRU: In Situ Resource Utilization

JSC: Johnson Space Center

KDP: Key Decision Point

KSC: Kennedy Space Center

LaRC: Langley Research Center

LED: Light Emitting Diode

LEO: Low Earth Orbit

LOCR: Lunar Operations Concept Review

LOX: Liquid Oxygen

LPCOR: Low Power $\mathrm{CO}_{2}$ Removal

LSS: Lunar Surface Systems

LT: Lunar Transport

LWCWT: Light Weight Contingency Water Treatment

MSFC: Marshall Space Flight Center

NASA: National Aeronautics and Space Administration

NGARS: Next Generation ARS

NP: NASA Publication

NPR: NASA Procedural Requirements

OD: Osmotic Distillation

PIC: Physicochemical

PDR: Preliminary Design Review

R\&TD: Research and Technology Development

SBAR: Sorbent-Based Atmosphere Revitalization

SDR: Systems Definition Review

SOE: Solid Oxide Electrolysis

SPR: Small Pressurized Rover

SRR: Systems Requirements Review

SIMA: Systems Integration, Modeling, and Analysis

TM: Technical Memorandum

TPP: Technology Prioritization Panel

TRL: Technology Readiness Levels

TSAC: Temperature Swing Adsorption Compressor

U.S.: United States

V\&T: Validation and Testing

VOC: Volatile Organic Carbon

VPCAR: Vapor Phase Catalytic Ammonia Removal

WBS: Work Breakdown Structure

WMS: Waste Management System

WRS: Water Recovery System 